\title{
Ascorbic Acid and Polyphenols Mediated Green Synthesis of Silver Nanoparticles from Tagetes erecta L. Aqueous Leaf Extract and Studied Their Antioxidant Properties
}

\author{
Pankaj Kumar Tyagi $\mathbb{D}^{1},{ }^{1}$ Shruti Tyagi, ${ }^{2}$ Deepak Gola, ${ }^{1}$ Arvind Arya, ${ }^{1}$ \\ Seyed Abdulmajid Ayatollahi $\mathbb{D}^{3,4}$ Mohammed M. Alshehri, ${ }^{5}$ and Javad Sharifi-Rad $\mathbb{D i}^{3}$ \\ ${ }^{1}$ Department of Biotechnology, Noida Institute of Engineering and Technology, Greater Noida, India \\ ${ }^{2}$ Young Scientist of UPCST Scheme, Department of Biotechnology, Noida Institute of Engineering and Technology, \\ Greater Noida, India \\ ${ }^{3}$ Phytochemistry Research Center, Shahid Beheshti University of Medical Sciences, Tehran, Iran \\ ${ }^{4}$ Department of Pharmacognosy and Biotechnology, School of Pharmacy, Shahid Beheshti University of Medical Sciences, \\ Tehran, Iran \\ ${ }^{5}$ Department of Pharmaceutical Care Services, Ministry of National Guard-Health Affairs, Riyadh, Saudi Arabia
}

Correspondence should be addressed to Pankaj Kumar Tyagi; pktgenetics@gmail.com, Seyed Abdulmajid Ayatollahi; majid_ayatollahi@yahoo.com, and Javad Sharifi-Rad; javad.sharifirad@gmail.com

Received 20 May 2021; Revised 14 July 2021; Accepted 20 July 2021; Published 3 August 2021

Academic Editor: José Agustín Tapia Hernández

Copyright (C) 2021 Pankaj Kumar Tyagi et al. This is an open access article distributed under the Creative Commons Attribution License, which permits unrestricted use, distribution, and reproduction in any medium, provided the original work is properly cited.

\begin{abstract}
Silver nanoparticle synthesis of the leaf extract Tagetes erecta L. enriched with ascorbic acid and polyphenols has been investigated. The color of the golden yellow extract has changed to pinkish-brown due to the reduction of $\mathrm{Ag}^{+}$to the colloidal solution of AgNPs and a sharp absorption peak at $420 \mathrm{~nm}$ under the UV-Vis spectrophotometer. In addition, the Fourier Transfer Infrared Spectroscopy (FTIR) estimation was completed in order to recognize and identify the biomolecules present in the extract acting as a reducing and capping agent for the AgNPs. The X-ray diffraction (XRD) peaks at (111), (201), (220), and (311) confirm the presence of monoclinic crystals in the solution. The morphology and size of the particles were provided by transmission electron microscopy (TEM) images of AgNPs. At a scale of $100 \mathrm{~nm}$, synthesized AgNPs were predominantly spherical with a size range of $7-35 \mathrm{~nm}$. In comparison to $7.39 \mathrm{mg} / 100 \mathrm{~g}$ in AgNPs, aqueous leaf extract was $55.14 \mathrm{mg} / 100 \mathrm{~g}$ higher in ascorbic acid. The phenolic and flavonoid content of extract was $52.54 \pm 2.15 \mathrm{mg}(\mathrm{GAE} / 100 \mathrm{~g})$ and $15.43 \pm 0.34 \mathrm{mg}(\mathrm{QE} / \mathrm{mL})$, and the colloidal AgNP solution was $21.45 \pm 1.15 \mathrm{mg}(\mathrm{GAE} / 100 \mathrm{~g})$ and $8.05 \pm 2.42 \mathrm{mg}(\mathrm{QE} / \mathrm{mL})$, respectively. Phenolic and flavonoid contents play a major role as a reducing agent and reduce the precursor $\mathrm{AgNO}_{3}$ into $\mathrm{AgNPs}$. The $\mathrm{DPPH}$ scavenging assay also assessed the antioxidant properties of extract and its derived AgNPs. As compared antioxidant value to aqueous leaf extract $(\mathrm{mg} / \mathrm{mL})$, higher percentage inhibition (PI) was found in AgNPs and free-radical scavenging activity of extract and AgNPs were directly linked to their concentrations. Results of this research have discovered a higher potential for free-radical scavenging AgNPs and will help to develop new and more potent antioxidants for the treatment of different diseases caused by oxidative stress; the higher antioxidant properties bearing AgNPs might be used.
\end{abstract}

\section{Introduction}

Today, a lot of novel protocols have been developed for silver nanoparticle (AgNP) synthesis with different shapes and sizes that has been attractive to nanotechnologist as well as biologist $[1,2]$. With five hundred tons of silver nanoparticles produced per year, silver is one of the most commercialized nanomaterials [3] and is expected to increase in the next few years. Numerous methods of silver nanoparticle synthesis are available in the scientific community physical as well 
as chemical in which the sol-gel process, chemical vapor deposition, chemical reduction, reverse micelle, microwave, hydrothermal method, laser-mediated synthesis, electroirradiation, microwave irradiation, ultraviolet (UV) irradiation, and photochemical reduction and biological methods from plants, microorganism, and yeast are common [4-8]. However, the synthesis of nanoparticles from materials (biological) such as plant leaves, stems, roots, and flowers is preferred due to their eco-friendly nature, cost-effectiveness, and less involvement of toxic chemicals for scientific community [9-11]. Therefore, the higher reduction rate and better stability of silver ions were observed in the extract of plant leaves as compared to microorganisms [11, 12]. Literatures available on different platforms regarding silver nanoparticle synthesis from biological material include plant leaf extracts from Azadirachta indica [13], Cassia tora [14], Dracocephalum moldavica [15], Elephantopus scaber [16], and Ziziphora tenuior [17]. The various parts of the plant extract [18, 19], black tea leaf [20-22], seeds like Mucuna pruriens [23], citrus fruits (Citrus limon, Citrus reticulata, and Citrus sinensis) aqueous extract of mushroom-mediated green synthesis $[24,25]$, and also flowers like Nyctanthes arbortristis [26] play a role as reductase and reduction of silver ions into silver nanoparticles [27]. Further, the application of silver nanoparticles is not limited to one area only [28]. For example, silver nanoparticles can act as antibacterial agents against pathogen bacteria such as $S$. aureus, L. monocytogenes, E. coli, $S$. enterica, and $P$. fluorescens $[9,11]$. Moreover, silver nanoparticles can be seen to play an important role in the remediation of multiple pollutants $[8,29]$. Despite the recent advances in the field of nanobiotechnology, we have not been able to establish exactly how different bioactive compounds in plants contribute in nanoparticle synthesis and why different plants exhibit different levels of nanoparticle synthesis even after applying the same protocol for the synthesis. One hypothesis for this is that each species has different levels of bioactive compounds and as some of these contribute greatly in nanoparticle synthesis, it is important to figure out their exact role in nanoparticle synthesis so that a standardized protocol for a large scale production could be developed which is a currently major drawback associated with biosynthesized nanoparticles that the amount of synthesized nanoparticles varies every time.

Hence, the aim of the present study was to investigate a rapid, simple, and eco-friendly approach for controlledsized silver nanoparticle synthesis using the extract of the leaf parts having a good amount of polyphenol and ascorbic acid of Tergate. Further, the role of phytochemical involved during the synthesis of silver nanoparticles was identified. In addition, this morphological characteristic of silver nanoparticles was examined through techniques like UV-Vis spectra, TEM, FTIR, and XRD. Further, the antioxidant activity of silver nanoparticles was examined for their potential application in the healthcare sector.

\section{Materials and Methods}

2.1. Materials and Reagents. The healthy leaves of Tagetes erecta were collected from the botanical garden of this insti- tute. Analytical grade reagents used in the study including 2,6-dichlorophenolindophenol (DCPIP or DPIP) or blue dye, $\alpha, \alpha$-diphenyl- $\beta$-picrylhydrazyl (DPPH), standard Lascorbic acid, 20\% glacial acetic acid, Folin-Ciocalteu reagent, sodium bicarbonate, methanol, and silver nitrate were purchased from HiMedia Laboratories and Sigma-Aldrich.

2.2. Preparation of the Plant Extract. $10 \mathrm{~g}$ leaves of plant were taken and thoroughly washed in distilled water and then crushed using mortar pestle. After crushing, the leaves mixed into $100 \mathrm{~mL}$ of deionized water followed by boiling for around $10 \mathrm{~min}$ at $60^{\circ} \mathrm{C}$. The aqueous leaf extract was filtered through a Whatman filter paper (No.1), centrifuged for up to $10 \mathrm{~min}$ at $5000 \mathrm{rpm}$. The supernatant was stored at $4^{\circ} \mathrm{C}$ for further applications.

\subsection{Preparation of the Dye and Standard Ascorbic Acid for} Determination of Vitamin $C$. The dye solution was prepared by dissolving $100 \mathrm{mg}$ of 2,6-dichlorophenolindophenol (blue dye) in $100 \mathrm{~mL}$ of distilled water. The mixture was diluted into 4 folds, filtrates, and was stored at $4^{\circ} \mathrm{C}$ for further use. $100 \mathrm{mg}$ standard L-ascorbic acid dissolved in $50 \mathrm{~mL}$ of $20 \%$ glacial acetic acid and diluted to $100 \mathrm{~mL}$ with distilled water.

2.4. Determination of Vitamin C by the Titration Method. $10 \mathrm{~mL}$ of the L-ascorbic acid solution was titrated with the blue dye solution. Each drop of the blue dye in contact with the L-ascorbic acid solution turns pink in color. The endpoint was reached when the pink color lasts for 15 seconds $[30,31]$. Similarly, $10 \mathrm{~mL}$ sample of Tagetes erecta prepared was in turn titrated and the titre values were recorded.

2.5. Determination of Phenolic Content. The amount of phenolic content in the extracts of Tagetes erecta was evaluated by Folin-Ciocalteu (F-C) assay as previously described by Velioglu et al. with some modification [32]. $200 \mu \mathrm{L}$ aqueous leaf extract sample was mixed with $1.5 \mathrm{~mL}$ of 10 times diluted F-C reagent. $1.5 \mathrm{~mL}$ of $6 \%(w / v)$ sodium bicarbonate was added after $5 \mathrm{~min}$ in the solution for neutralized purposes. The solution was kept 90 min in dark and further takes an absorbance at $760 \mathrm{~nm}$. Phenolic contents were calculated by using the Gallic acid equivalent standard curve. Results were expressed as $\mathrm{mg} / \mathrm{mL}$ of Gallic acid equivalent (GAE).

2.6. Determination of Flavonoid Content. Flavonoid content in the leaf extract of Tagetes erecta was determined through the colorimetric method as described by Woisky and Salatino with some modification [33]. 0.5 and $1 \mu \mathrm{L} / \mathrm{mL}$ aqueous leaf extract was mixed with $1.5 \mathrm{~mL}$ of ethanol with $0.1 \mathrm{~mL}(10 \%$ aluminum chloride) and $2.8 \mathrm{~mL}$ of $\mathrm{dH}_{2} 0$. The mixed reaction solution was shaken at RT for $20 \mathrm{~min}$, and then, absorption was monitored at $415 \mathrm{~nm}$. Quercetin equivalent was used as a standard. The amount of total flavonoid was expressed as quercetin equivalent (QE).

2.7. Green Synthesis of Silver Nanoparticles. Silver nanoparticle synthesis from leaf extract of Tagetes erecta was determined by the biological method as describe by Tyagi et al. with some modification [34]. $1 \mathrm{mM}$ liquid silver nitrate $\left(\mathrm{AgNO}_{3}\right)$ was ready in $100 \mathrm{~mL}$ deionized water. Aqueous leaf 


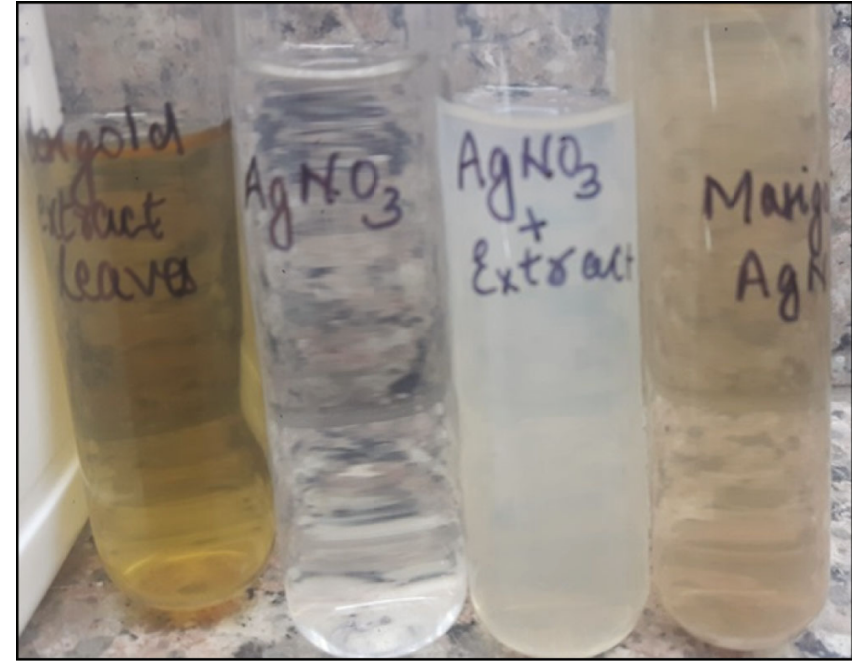

(a)

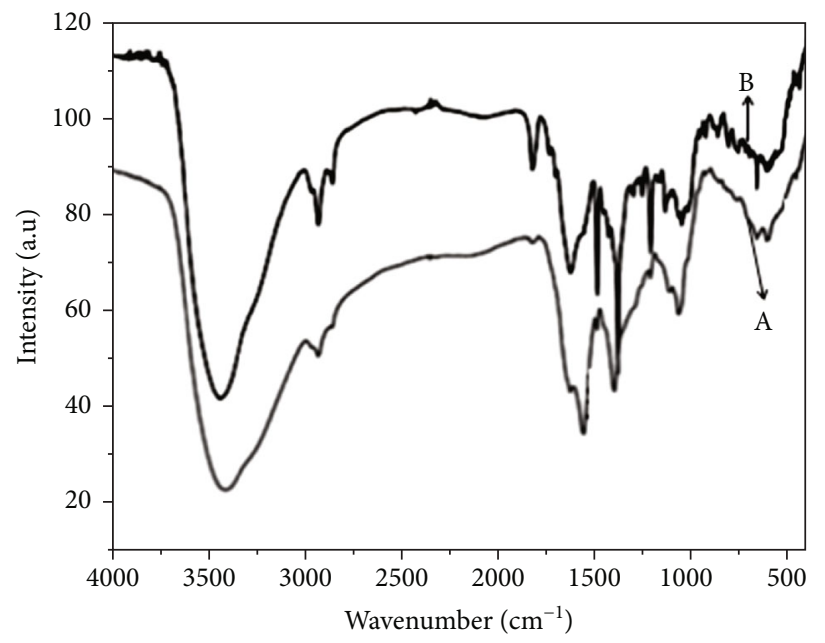

(c)

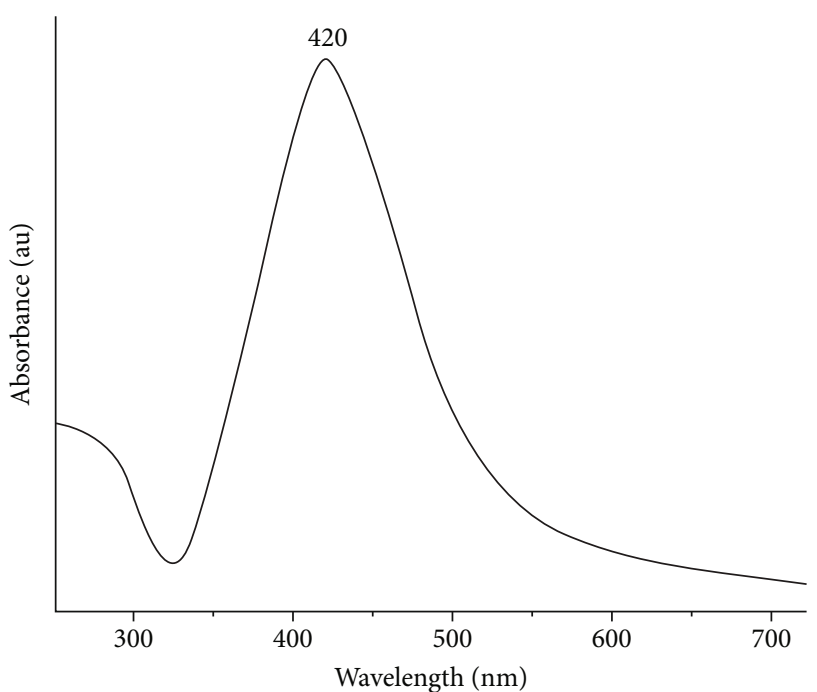

(b)

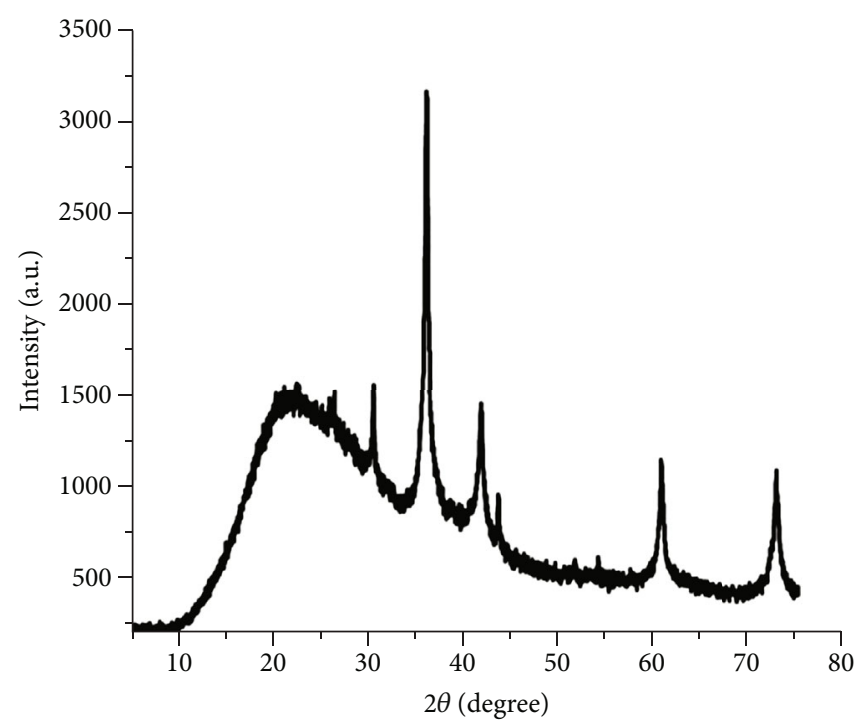

(d)

FIGURE 1: Visual color changing process from extracts to AgNP formation of Tagetes erecta L. (a), UV-Vis spectra analysis of AgNPs (b), FTIR spectra comparative analysis of Tagetes erecta L. and AgNPs (c), and X-ray diffraction pattern of the AgNPs (d).

extract $(90 \mathrm{~mL})$ of Tagetes erecta was added drop by drop in a flask bearing with $10 \mathrm{~mL}$ of liquid solution silver nitrate $(1 \mathrm{mM})$, and $\mathrm{pH}$ was adjusted to near 7.2. The solution containing a flask was kept under direct sunlight for up to $30 \mathrm{~min}$ and wait for reduction from $\mathrm{Ag}^{+}$ion to colloidal $\mathrm{Ag}^{0}$. The formations of AgNPs were confirmed by color changing from golden yellow to pinkish-brown. Primary confirmed synthesized AgNPs were purified through centrifugation process at $10,000 \mathrm{rpm}$ for $25 \mathrm{~min}$ and again redispersed into deionized water for eliminating the water-soluble residues.

2.8. Determination of Antioxidant Properties. Antioxidant properties were determined by using $\alpha, \alpha$-diphenyl- $\beta$-picrylhydrazyl (DPPH) as a free-radical scavenging assay described by Chang et al., after some modification [35]. Dissolved $1.9 \mathrm{mg}$
DPPH in $100 \mathrm{~mL}$ methanol and shake for $10 \mathrm{~min}$ or up to $\mathrm{DPPH}$ dissolved in solvent. DPPH $(2.97 \mathrm{~mL})$ was added to the different concentrations of samples (200, 400, and $600 \mu \mathrm{g} / \mathrm{mL}$ ) prepared in methanol. The reaction solution was kept at RT for $20 \mathrm{~min}$ in darkness. The absorbance of the reaction sample was monitored under UV-Visible at $517 \mathrm{~nm}$. Here, DPPH was used as the control sample. The PI value of scavenging was determined as follows: [(Absorbance ${ }_{\text {control }}-$ Absorbance $\left._{\text {sample }}\right) /\left(\right.$ Absorbance $\left.\left._{\text {control }}\right)\right] \times 100$. Mean value (M) and standard error (SE) were calculated by performing the experiments three times.

2.9. Characterization of Silver Nanoparticles. Characterizations of AgNPs were done with the help of different nanotechnology techniques. Primary confirmation of AgNPs was 
TABLE 1: Peak position and assignment of main IR absorption bands of aqueous leaf extract and silver nanoparticles.

\begin{tabular}{|c|c|c|c|}
\hline S. No. & Sample & $\begin{array}{c}\text { Peak position } \\
\text { wavenumber }\left(\mathrm{cm}^{-1}\right)\end{array}$ & Peak assignment \\
\hline \multirow{7}{*}{1} & \multirow{7}{*}{ Aqueous leaf extract } & 3415 & O-H stretching (alcohol \& phenol) \\
\hline & & 2922 & $\mathrm{C}-\mathrm{H}$ stretching (alkanes) \\
\hline & & $1829,1399, \& 1060$ & $\begin{array}{c}\mathrm{C}-\mathrm{O} \text { stretching and } \mathrm{C}=\mathrm{O} \text { stretching (alcohol, ethers, carboxylic acids, } \\
\text { and esters all have carbonyl functional groups) }\end{array}$ \\
\hline & & $1643-1564$ & N-H stretching (amide linkages of proteins) \\
\hline & & 1490 & $\mathrm{C}=\mathrm{C}$ stretching (aromatic compounds) \\
\hline & & 670 & $\mathrm{O}-\mathrm{H}$ bend \\
\hline & & 609 & $\mathrm{C}-\mathrm{H}$ bending \\
\hline \multirow{3}{*}{2} & \multirow{3}{*}{ Silver nanoparticles (AgNPs) } & 3388 & O-H stretching (alcohol \& phenol) \\
\hline & & 2933 & C-H stretching (hydrocarbons such as alkanes \& aldehydes) \\
\hline & & $1829,1399, \& 1060$ & $\begin{array}{l}\mathrm{C}-\mathrm{O} \text { stretching and } \mathrm{C}=\mathrm{O} \text { stretching of carbonyl bands shifted } \\
\text { (clearly indicating the coordination of carboxylic acid with AgNPs) }\end{array}$ \\
\hline
\end{tabular}

based on color changes in the colloidal solution. Furthermore, confirmations of the synthesis of AgNPs, the absorption plasmon peak of the colloidal solution, were recorded under a UV-Vis spectrophotometer by scanning the spectra. The involvement of the functional group in $\mathrm{Ag}^{+}$reduction and applying formation of the phytofabrication aqueous leaf extract-mediated AgNPs were studied using FTIR. The size and shape of nanoparticles were analyzed under TEM. The XRD of AgNPs analyzed and determined the particle size by using the Debye-Schrrer equation.

\section{Results and Discussion}

3.1. Characterization of Silver Nanoparticles. Leaf extract of Tagetes erecta visual color golden yellow changes into pinkish-brown, this may be done to the reduction of $\mathrm{Ag}^{+}$from $\mathrm{AgNO}_{3}$ into the $\mathrm{Ag}^{0}$ in the colloidal solution of AgNPs, and a sharp absorption peak was obtained at $420 \mathrm{~nm}$ under a $\mathrm{UV}-\mathrm{V}$ is spectrophotometer. These color changes and sharp peaks confirm the biosynthesis of colloidal AgNP formation in the solution (Figures 1(a) and 1(b)). In some previous reports, a plasmon peak ranging 400-500 nm in AgNP formation [36] and some reports evident the absorption peak at $350-450 \mathrm{~nm}$ for the silver nanoparticles [27]. All in all, some factors such as size and shape of nanoparticles present in the reaction solution may be affecting the SPR absorbance.

The FTIR spectra of aqueous leaf extract and AgNPs synthesized from Tagetes erecta were compared. Aqueous leaf extract (A) and AgNPs (B) have FTIR peaks at 3415, 2922, $1829,1643,1564,1490,1399,1060,670$, and $609 \mathrm{~cm}^{-1}$, respectively. The $\mathrm{O}-\mathrm{H}$ stretching vibration of alcohol and phenol compounds is assigned to the band at $3415 \mathrm{~cm}^{-1}$, while the $\mathrm{C}-\mathrm{H}$ stretching mode in alkanes is assigned to the band at $2922 \mathrm{~cm}^{-1}$. The $\mathrm{C}-\mathrm{O}$ stretching and $\mathrm{C}=\mathrm{O}$ stretching modes of the carbonyl functional groups in alcohol, ethers, carboxylic acids, and esters are responsible for the FTIR bands observed at 1399, 1060, and $1829 \mathrm{~cm}^{-1}$. N-H bending vibration of amides was attributed to the bands at 1643 and $1564 \mathrm{~cm}^{-1}$. The $\mathrm{C}=\mathrm{C}$ stretching mode in aromatic compounds is assigned to the bands at $1490 \mathrm{~cm}^{-1}$. O-H bend and $\mathrm{C}-\mathrm{H}$ bending are responsible for the peaks at 670 and $609 \mathrm{~cm}^{-1}$, respectively (Table 1). The C-H stretching (alkanes) at $2922 \mathrm{~cm}^{-1}$ and the carbonyl bands at $1829 \mathrm{~cm}^{-1}$ were shifted to $2917 \mathrm{~cm}^{-1}$ and $1819 \mathrm{~cm}^{-1}$, respectively, during the formation of AgNPs. The reduction of $\mathrm{Ag}^{+}$from $\mathrm{AgNO}_{3}$ into $\mathrm{Ag}^{0}$ thought biosynthesis process with the help of reeducates and capping material present within the leaf extract with the functional groups of the regions $2922 \mathrm{~cm}^{-1}$ (Figure 1(c)). FTIR often used to recognize and identify the biomolecules act as a reducing and capping agent for AgNPs. Both reduction and capping events contribute significantly in the process of AgNPs, and during this process, the various phytoconstituents such as alkaloids, amino acids, flavonoids, steroids, glycosides, tannins, and phenolic contents are involved for the synthesis and stabilization of AgNPs by forming different linkages with silver ions. The plant leaf extracts having a higher quantity of vitamin $C$ and polyphenols contributed a significant role for the stable biosynthesis of nanoparticles. Changes within the intensity of FTIR peaks and small shifts were observed in the spectra of the extract and therefore the nanoparticles. This could ensure to the coordination of phytochemicals with the metal surface [37]. Necessary linkages like $\mathrm{C}=\mathrm{O},-\mathrm{C}-\mathrm{OC}-, \mathrm{N}-\mathrm{H},-\mathrm{C}=\mathrm{C}-$, $-\mathrm{C}=\mathrm{C}-\mathrm{H}$, and $\mathrm{C}-\mathrm{H}$ are formed during the process of nanoparticle synthesis [38]. Similar linkages were also observed in this investigation.

Synthesized AgNPs were studied through XRD for more analysis of its crystalline nature. Results of XRD represent the crystalline planes showing peaks and characteristics of nanoparticles (Figure $1(\mathrm{~d})$ ). The four main diffraction peaks for dried AgNPs were observed at 2 theta = 38.4, 44.5, 64.4, and 77.8, respectively; these peaks were corresponding to (111), (201), (220), and (311) planes of the face-centred cubic crystal structure of silver. Obtained results of XRD are in agreement with the previously published research confirming the cubic structure of silver [39, 40]. Similar XRD were recorded in Erigeron bonariensis [41] and Alternaria solani [42].

TEM pictures give more insight into the morphology, size, form, and distribution profile of the AgNPs. TEM 


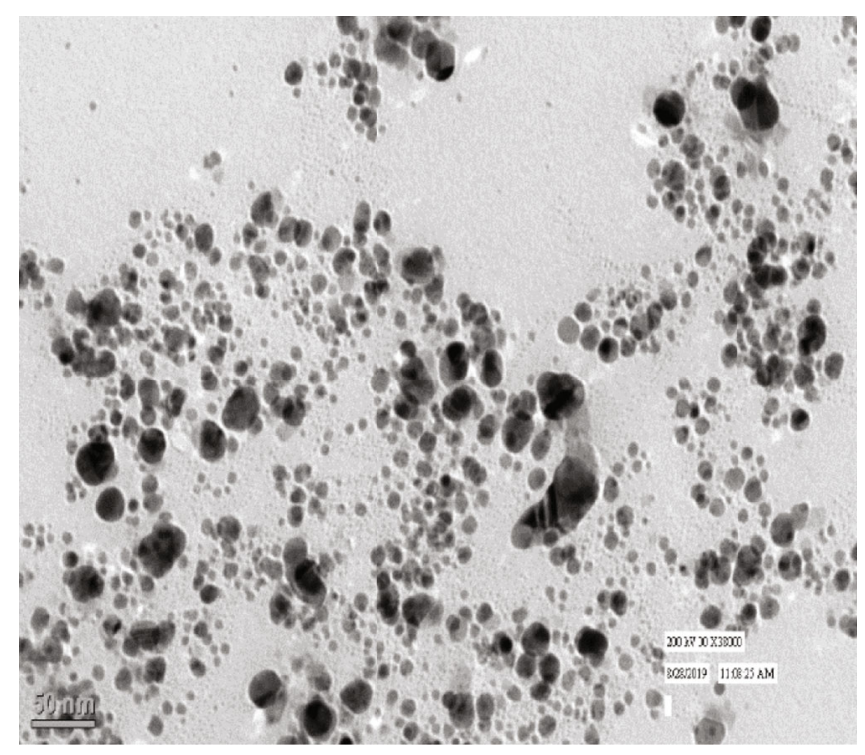

(a)

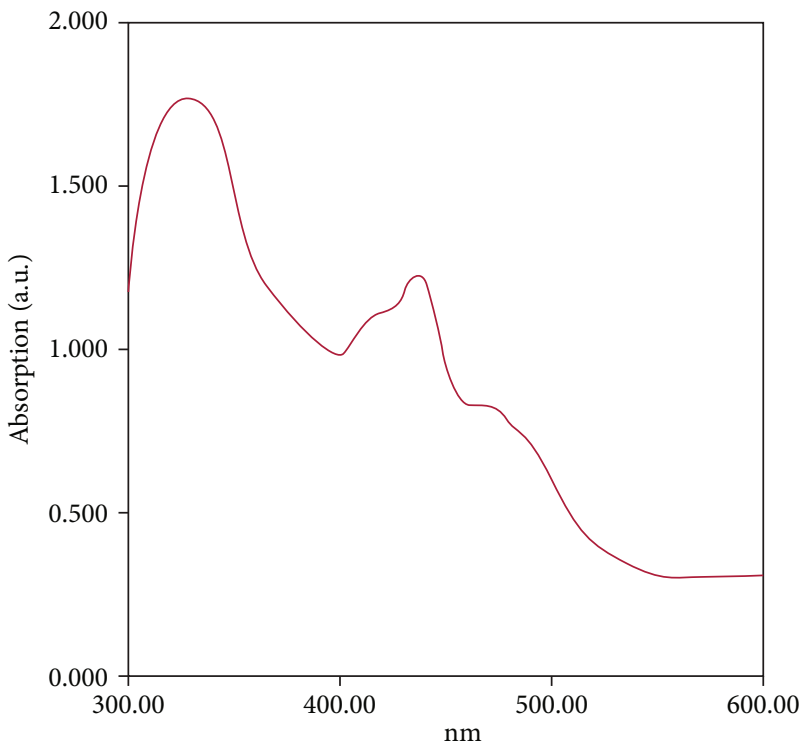

(c)

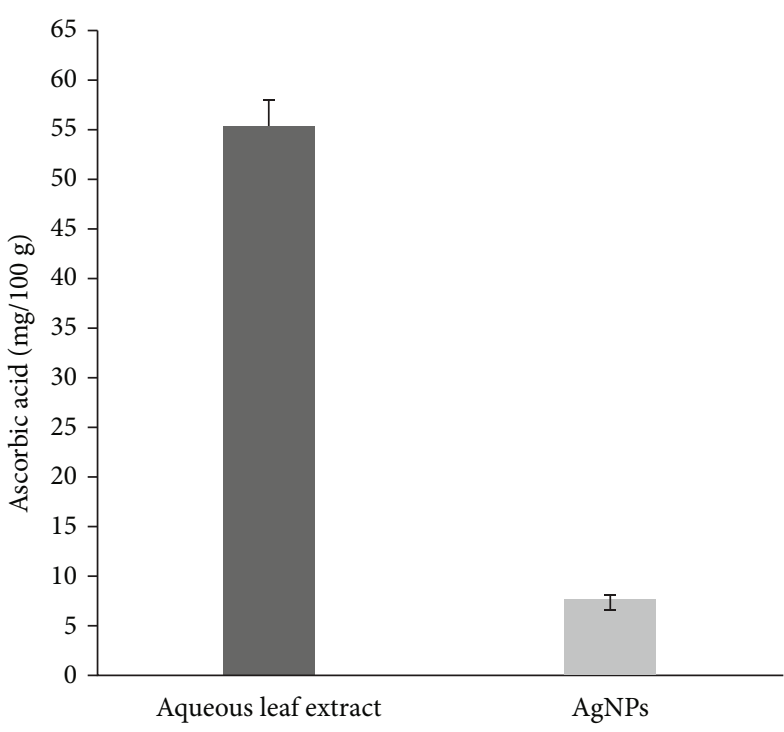

Aqueous leaf extract

AgNPs

(b)

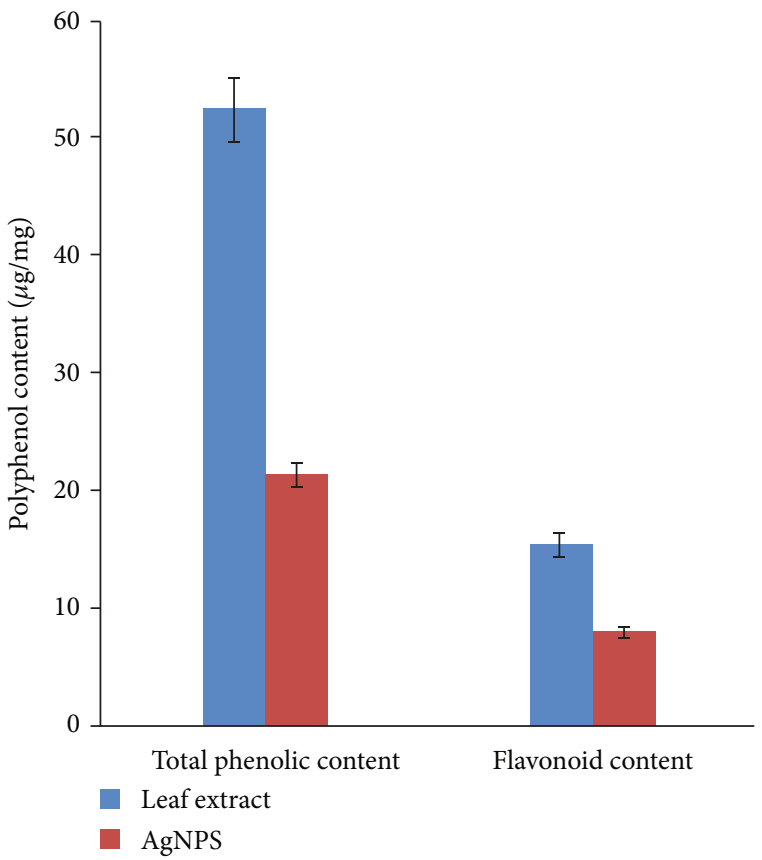

(d)

Figure 2: TEM results of AgNPs showing different sizes and shapes: (a) a comparative analysis of ascorbic acid (mg/100 g) between aqueous leaf extract of Tagetes erecta L. and AgNPs; (b) the absorption peak of aqueous leaf extract of Tagetes erecta L.; (c) the total phenolic and flavonoid content of aqueous leaf extract of Tagetes erecta L. and AgNP colloidal suspension.

pictures of AgNPs show the various shapes such as circular, rounded, triangle, and spherical, but mainly spherical in shapes with smooth surface nanoparticles were predominant. Synthesized AgNPs were predominantly spherical shape with the size range of $7-35 \mathrm{~nm}$ (average size of $22 \mathrm{~nm}$ ) at $50 \mathrm{~nm}$ scale (Figure 2(a)). Biosynthesis of smooth and spherical nanoparticles has been reported in Sida cordifolia [37], Aes- culus hippocastanum [43], Rheum emodi [44], and honeymediated green synthesis of silver nanoparticles [45]. TEM pictures additionally indicated the formation of aggregates of AgNPs. In these aggregates, the particles were not directly connected to every alternative. This implies that the nanoparticles were stable by the aqueous leaf extract of Tagetes erecta that acted as a capping agent. 


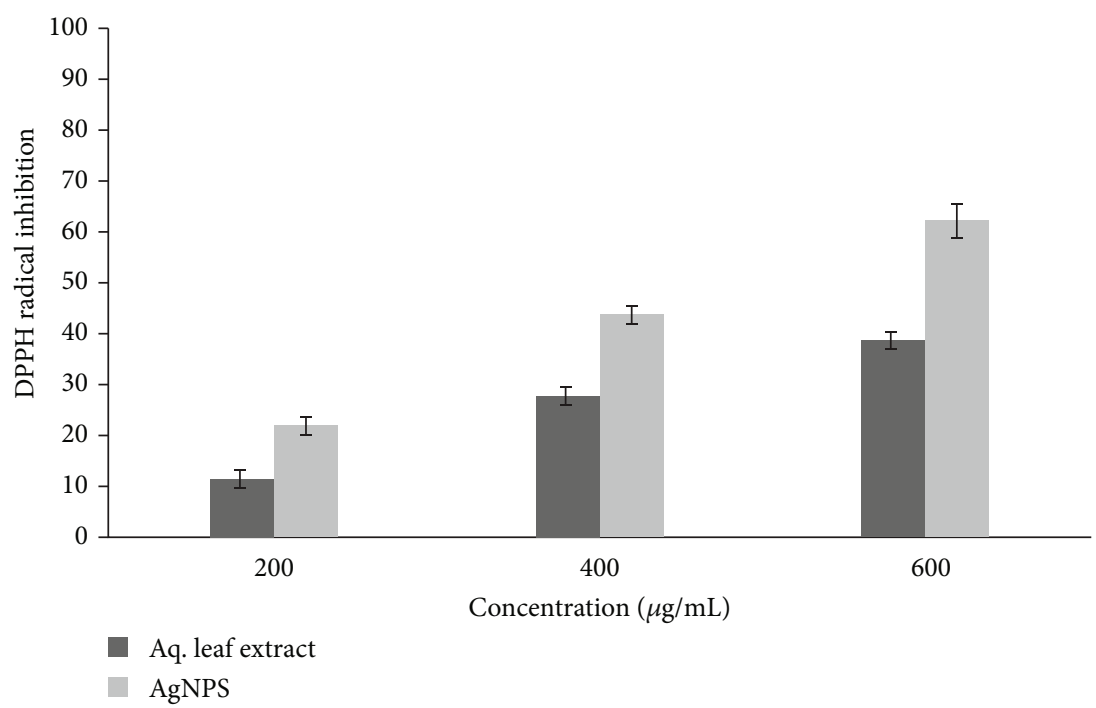

Figure 3: Antioxidant activity (\% inhibition) of aqueous leaf extract of Tagetes erecta $L$ and its derived AgNPs assessed by DPPH scavenging assay.

3.2. Estimation of Ascorbic Acid. Ascorbic acid was estimated in both Tagetes erecta aqueous leaf extract and its derived silver nanoparticles.

3.2.1. Ascorbic Acid in Extract. $6.5 \mathrm{~mL}$ of the 2,6-dichlorophenolindophenol (blue dye solution) was required to titrate $10 \mathrm{~mL}$ of the ascorbic acid (L-ascorbic acid) solution which contained $1 \mathrm{mg}$ of ascorbic acid per $\mathrm{mL}$.

That is, $6.5 \mathrm{~mL}$ blue dye solution is required to titrate, $10 \mathrm{mg}$ ascorbic acid.

Therefore, $1 \mathrm{~mL}=(10 / 6.5)=1.54 \mathrm{mg}$.

For Tagetes erecta aqueous leaf extract, the average $\mathrm{mL}$ of the blue dye used was $3.58 \mathrm{~mL}$.

That is, $3.58 \mathrm{~mL}=1.54 \times 3.58=5.514 \mathrm{mg}$.

Therefore, $100 \mathrm{~mL}$ of the Tagetes erecta aqueous leaf extract contains $55.14 \mathrm{mg} / 100 \mathrm{~g}$ ascorbic acid.

3.2.2. Ascorbic Acid in Colloidal Solution of AgNPs. $10 \mathrm{~mL}$ colloidal solution of AgNPs was titred, $0.48 \mathrm{~mL}$ blue dye solution, and contains $0.739 \mathrm{mg}$ ascorbic acid.

That is, $0.48 \mathrm{~mL}=1.54 \times 0.48=0.739 \mathrm{mg}$.

Therefore, $100 \mathrm{~mL}$ of AgNPs synthesized from Tagetes erecta contained $7.39 \mathrm{mg} / 100 \mathrm{~g}$ of ascorbic acid.

All in all, it is concluded that the higher amount of ascorbic acid content was $55.14 \mathrm{mg} / 100 \mathrm{~g}$ in Tagetes erecta leaf extract as compared to $7.39 \mathrm{mg} / 100 \mathrm{~g}$ in AgNPs (Figure 2(b)). The similar results were obtained in earlier reports in Hibiscus rosa-sinensis and Citrus sinensis [46], Chenopodium and Marigold [30], onion extract [47], and leaf extract of Psidium guajava [48].

3.3. Estimation of Total Phenolic and Flavonoid Content in Extract and AgNPs. The absorbance peak of Tagetes erecta aqueous leaf extract was observed at $370 \mathrm{~nm}$, which is typical showing the presence of flavonoid (Figure 2(c)). The total phenolic and flavonoid content of Tagetes erecta aqueous leaf extract $52.54 \pm 2.15 \mathrm{mg}(\mathrm{GAE} / 100 \mathrm{~g})$ and $15.43 \pm 0.34 \mathrm{mg}$
(QE/mL) and the colloidal solution of AgNPs $21.45 \pm$ $1.15 \mathrm{mg}(\mathrm{GAE} / 100 \mathrm{~g})$ and $8.05 \pm 2.42 \mathrm{mg}(\mathrm{QE} / \mathrm{mL})$ were estimated, respectively (Figure $2(\mathrm{~d})$ ). The obtained results conclude that the higher amount of total phenolic and flavonoid content was in the extract as compared to AgNPs. Total phenolic and flavonoid content aqueous leaf extract of Tagetes erecta may be played a role as a reducing agent and reduce the precursor $\mathrm{AgNO}_{3}$ solution to colloidal AgNP solution. Extract of other plants contains different constituents with different functional groups, which act as reducing agents for reduction of silver ions to colloidal solution of nanoparticles. Extracts of leaf [46, 49], stem [50], fruit [51], bark [52], and root [53] have a potential for reduction of silver ions to colloidal solution of nanoparticles as cited by several workers. Furthermore, the above-mentioned results are evident for about a two-fold increase of the total phenolic content and flavonoids in Tagetes erecta aqueous leaf extract as compared to their derived colloidal solution of AgNPs. Phenolic content and flavonoids have been reported to be the most important phytochemicals responsible for the antioxidant capacity also. Plant-derived polyphenols display characteristic inhibition patterns toward the oxidative response. Thus, the higher amount of phenolic content and flavonoids in Tagetes erecta leaf extract can be taken as a fine indication of its higher antioxidant capability. Therefore, it may be concluded that the AgNPs biosynthesized from the leaf of Tagetes erecta possess high antioxidant activity which further suggest their therapeutic potential or can be used as a natural, renewable, and low-cost bioreducing agent. Tagetes erecta leaf extract could be used as an efficient green reducing agent for the production of AgNPs and can be explored for its applications in the prevention of free-radical-related diseases. On comparing with the earlier report in Syzygium cumini recorded higher total phenolic and flavonoid contents in plant extract than the AgNPs [54], Asphodelus aestivus Brot. extract can be used efficiently in the production of potential antioxidant AgNPs for commercial application [55]. 
3.4. Estimation of Antioxidant Activity in Aqueous Leaf Extract and AgNPs. Antioxidant activity of Tagetes erecta aqueous leaf extract and its derived AgNPs were assessed by DPPH scavenging assay and found the percentage of inhibition (PI) value $11.55 \pm 0.12,27.78 \pm 1.34$, and $38.56 \pm 1.12$ in aqueous leaf extract and $21.45 \pm 0.44,43.57 \pm 0.87$, and $62.58 \pm 0.55$ in AgNPs at different concentrations of the sample $200,400,600 \mu \mathrm{g} / \mathrm{mL}$, respectively (Figure 3 ). The higher PI value was found in AgNPs as compared to aqueous leaf extract in all the three concentrations $(\mu \mathrm{g} / \mathrm{mL})$. Therefore, it may be concluded that the free-radical scavenging activity of aqueous leaf extract and AgNPs was directly related to their concentrations. On the other hand, we can say that the antioxidant activities are concentration-dependent and this trend was observed in both aqueous leaf extract and AgNPs.

$\mathrm{DPPH}$ is a stable and recognized synthetic solid radical for evaluating of antioxidant potential of compounds. The reducing power of compounds is directly proportional to their antioxidant activity. DPPH was reduced by accepting the hydrogen or electrons from silver nanoparticles, and this mechanism was quantified changing the color from purple to yellow by a spectrophotometer. This assay is frequently used in the measurement of the free-radical scavenging capacity of compounds present in medicinal plant extracts [56]. These results revealed that the AgNPs had greater free-radical scavenging potential than aqueous leaf extract of Tagetes erecta. Similar trends of enhanced DPPH scavenging activity by silver, platinum, and selenium, gold nanoparticles were observed by various workers $[57,58]$. All in all, AgNPs may be useful for the development of newer and more potent antioxidants. The AgNPs having higher antioxidant properties could be used as treatment agents of many diseases caused by oxidative stress.

\section{Conclusion}

In the present study, the leaf extract of Tagetes erecta was used for the synthesis of silver nanoparticles. It was observed that the leaf extract contains multiple phytochemicals that play an important role (reducing as well as capping) during the synthesis of stable silver nanoparticles. Further, FTIR analysis confirms the role of phytochemicals during the synthesis of silver nanoparticles. Tagetes erecta leaf extract has a higher phenolic content and flavonoids, which indicates that it has a higher antioxidant capacity. As a result, AgNPs biosynthesized from Tagetes erecta leaf have a high antioxidant activity, implying that they have therapeutic potential or can be used as a natural, renewable, and low-cost bioreducing agent. Tagetes erecta leaf extract has the potential to be used as a green reducing agent for the production of AgNPs, as well as for the prevention of free-radical-related diseases. Moreover, significant antioxidant activity was observed for the plant-based nanoparticles and shows its potential application in the healthcare sector and could be used as treatment agents of many diseases caused by oxidative stress.

\section{Data Availability}

The data used to support the findings of this study are available from the corresponding author upon request.

\section{Conflicts of Interest}

The authors declare that they have no conflict of interest.

\section{Acknowledgments}

Author ST gratefully acknowledges CST, Uttar Pradesh (Grant no: CST/8276 (Young Scientist Scheme)) for funds. The authors also acknowledge the constant support from the director of this institute.

\section{References}

[1] V. K. Sharma, R. A. Yngard, and Y. Lin, "Silver nanoparticles: green synthesis and their antimicrobial activities," in Advances in Colloid and Interface Science, vol. 145, pp. 83-96, Elsevier, 2009.

[2] V. Gopinath, D. MubarakAli, S. Priyadarshini, N. M. Priyadharsshini, N. Thajuddin, and P. Velusamy, "Biosynthesis of silver nanoparticles from Tribulus terrestris and its antimicrobial activity: A novel biological approach," Colloids and Surfaces B: Biointerfaces, vol. 96, pp. 69-74, 2012.

[3] C. Larue, H. Castillo-Michel, S. Sobanska et al., "Foliar exposure of the crop Lactuca sativa to silver nanoparticles: evidence for internalization and changes in Ag speciation," Journal of Hazardous Materials, vol. 264, pp. 98-106, 2014.

[4] Y. L. N. Murthy and T. Kondala Rao, "Synthesis and characterization of nano silver ferrite composite," Journal of Magnetism and Magnetic Materials, vol. 322, no. 14, pp. 2071-2074, 2010.

[5] M. R. Bindhu and M. Umadevi, "Antibacterial and catalytic activities of green synthesized silver nanoparticles," Spectrochimica Acta Part A: Molecular and Biomolecular Spectroscopy, vol. 135, pp. 373-378, 2015.

[6] S. M. Pourmortazavi, M. Taghdiri, V. Makari, and M. RahimiNasrabadi, "Procedure optimization for green synthesis of silver nanoparticles by aqueous extract of Eucalyptus oleosa," Spectrochimica Acta Part A: Molecular and Biomolecular Spectroscopy, vol. 136, pp. 1249-1254, 2015.

[7] P. R. Rathi Sre, M. Reka, R. Poovazhagi, M. Arul Kumar, and K. Murugesan, "Antibacterial and cytotoxic effect of biologically synthesized silver nanoparticles using aqueous root extract of Erythrina indica lam," Spectrochimica Acta Part A: Molecular and Biomolecular Spectroscopy, vol. 135, pp. 11371144, 2015.

[8] D. Gola, A. kriti, N. Bhatt et al., "Silver nanoparticles for enhanced dye degradation," Current Research in Green and Sustainable Chemistry, vol. 4, article 100132, 2021.

[9] F. Rodríguez-Félix, A. G. López-Cota, M. J. Moreno-Vásquez et al., "Sustainable-green synthesis of silver nanoparticles using safflower (Carthamus tinctorius L.) waste extract and its antibacterial activity," Heliyon, vol. 7, no. 4, p. e06923, 2021.

[10] E. Sreelekha, B. George, A. Shyam, N. Sajina, and B. Mathew, "A comparative study on the synthesis, characterization, and antioxidant activity of green and chemically synthesized silver nanoparticles," Bionanoscience., vol. 11, no. 2, pp. 489-496, 2021.

[11] A. Salayová, Z. Bedlovičová, N. Daneu et al., "Green synthesis of silver nanoparticles with antibacterial activity using various medicinal plant extracts: morphology and antibacterial efficacy," Nanomaterials, vol. 11, no. 4, p. 1005, 2021.

[12] M. F. Zayed, W. H. Eisa, and A. A. Shabaka, "Malva parviflora extract assisted green synthesis of silver nanoparticles," 
Spectrochimica Acta Part A: Molecular and Biomolecular Spectroscopy, vol. 98, pp. 423-428, 2012.

[13] A. Tripathy, A. M. Raichur, N. Chandrasekaran, T. C. Prathna, and A. Mukherjee, "Process variables in biomimetic synthesis of silver nanoparticles by aqueous extract of Azadirachta indica (Neem) leaves," Journal of Nanoparticle Research, vol. 12, no. 1, pp. 237-246, 2010.

[14] A. Saravanakumar, M. Ganesh, J. Jayaprakash, and H. T. Jang, "Biosynthesis of silver nanoparticles using Cassia tora leaf extract and its antioxidant and antibacterial activities," Journal of Industrial and Engineering Chemistry, vol. 28, pp. 277-281, 2015.

[15] Y. Park, H. J. Noh, L. Han et al., “Artemisia capillaris Extracts as a green factory for the synthesis of silver nanoparticles with antibacterial activities," Journal of Nanoscience and Nanotechnology, vol. 12, no. 9, pp. 7087-7095, 2012.

[16] S. N. Kharat and V. D. Mendhulkar, "Synthesis, characterization and studies on antioxidant activity of silver nanoparticles using Elephantopus scaber leaf extract," Materials Science and Engineering: C, vol. 62, pp. 719-724, 2016.

[17] B. Sadeghi and F. Gholamhoseinpoor, "A study on the stability and green synthesis of silver nanoparticles using Ziziphora tenuior (Zt) extract at room temperature," Spectrochimica Acta Part A: Molecular and Biomolecular Spectroscopy, vol. 134, pp. 310-315, 2015.

[18] B. Thomas, B. S. M. Vithiya, T. A. A. Prasad et al., "Antioxidant and photocatalytic activity of aqueous leaf extract mediated green synthesis of silver nanoparticles using Passiflora edulis f. flavicarpa," Journal of Nanoscience and Nanotechnology, vol. 19, no. 5, pp. 2640-2648, 2018.

[19] S. Tyagi, A. Kumar, and P. K. Tyagi, "Comparative analysis of metal nanoparticles synthesized from Hibiscus rosa-sinesis and their antibacterial activity estimation against nine pathogenic bacteria," Asian Journal of Pharmaceutical and Clinical Research, vol. 10, no. 5, pp. 323-329, 2017.

[20] N. A. Begum, S. Mondal, S. Basu, R. A. Laskar, and D. Mandal, "Biogenic synthesis of $\mathrm{Au}$ and $\mathrm{Ag}$ nanoparticles using aqueous solutions of black tea leaf extracts," Colloids and Surfaces B: Biointerfaces, vol. 71, no. 1, pp. 113-118, 2009.

[21] D. Arumai Selvan, D. Mahendiran, R. Senthil Kumar, and R. A. Kalilur, "Garlic, green tea and turmeric extractsmediated green synthesis of silver nanoparticles: Phytochemical, antioxidant and_in vitro_cytotoxicity studies," Journal of Photochemistry and Photobiology B: Biology, vol. 180, pp. 243252, 2018.

[22] W. Zhang and W. Jiang, "Antioxidant and antibacterial chitosan film with tea polyphenols-mediated green synthesis silver nanoparticle via a novel one-pot method," International Journal of Biological Macromolecules, vol. 155, pp. 1252-1261, 2020.

[23] J. G. Longhi, E. Perez, J. J. de Lima, and L. M. B. Cândido, "In vitro evaluation of Mucuna pruriens (L.) DC. antioxidant activity," Brazilian Journal of Pharmaceutical Sciences, vol. 47, no. 3, pp. 535-544, 2011.

[24] M. V. Sujitha and S. Kannan, "Green synthesis of gold nanoparticles using Citrus fruits (Citrus limon, Citrus reticulata and Citrus sinensis) aqueous extract and its characterization," Spectrochimica Acta Part A: Molecular and Biomolecular Spectroscopy, vol. 102, pp. 15-23, 2013.

[25] A. Aygün, S. Özdemir, M. Gülcan, K. Cellat, and F. Şen, "Synthesis and characterization of Reishi mushroom-mediated green synthesis of silver nanoparticles for the biochemical applications," Journal of Pharmaceutical and Biomedical Analysis, vol. 178, p. 112970, 2020.

[26] R. K. Das, N. Gogoi, and U. Bora, "Green synthesis of gold nanoparticles using Nyctanthes arbortristis flower extract," Bioprocess and Biosystems Engineering, vol. 34, no. 5, pp. 615-619, 2011.

[27] S. Tyagi, P. K. Tyagi, D. Gola, N. Chauhan, and R. K. Bharti, "Extracellular synthesis of silver nanoparticles using entomopathogenic fungus: characterization and antibacterial potential," SN Applied Sciences, vol. 1, no. 12, pp. 1-9, 2019.

[28] D. Garg, A. Sarkar, P. Chand et al., "Synthesis of silver nanoparticles utilizing various biological systems: mechanisms and applications - a review," Progress in Biomaterials, vol. 9, no. 3, pp. 81-95, 2020.

[29] A. Kaushik, D. Gola, J. Raghav et al., "Synthesis of silver nanoparticles using egg white: dye degradation and antimicrobial potential," Biointerface Research in Applied Chemistry, vol. 12, no. 2, pp. 2361-2372, 2022.

[30] S. Tyagi, "Role of phytochemicals on biosynthesis of silver nanoparticles from plant extracts and their concentration dependent toxicity impacts on Drosophila melanogaster," Biological Insights, vol. 1, pp. 21-28, 2016.

[31] P. K. Tyagi and S. Tyagi, "Comparative analysis of ascorbic and phenol content percentage in leaves, stems and flowers of Hibiscus rosa sinensis," Der Pharmacia Lettre, vol. 9, no. 12, pp. 4552, 2017, https://scholarsresearchlibrary.com/archive.html.

[32] Y. S. Velioglu, G. Mazza, L. Gao, and B. D. Oomah, "Antioxidant activity and total phenolics in selected fruits, vegetables, and grain products," Journal of Agricultural and Food Chemistry, vol. 46, no. 10, pp. 4113-4117, 1998.

[33] R. G. Woisky and A. Salatino, "Analysis of propolis: some parameters and procedures for chemical quality control," Journal of Apicultural Research, vol. 37, no. 2, pp. 99-105, 1998.

[34] P. K. Tyagi, V. Sarsar, and A. Ahuja, "Synthesis of metal nanoparticals: a biological prospective for analysis," Internationalt Journal of Pharmaceutical Innovation, vol. 2, no. 4, pp. 4860, 2012.

[35] C. C. Chang, M. H. Yang, H. M. Wen, and J. C. Chern, "Estimation of total flavonoid content in propolis by two complementary colometric methods," Journal of Food and Drug Analysis, vol. 10, 2002.

[36] P. K. Tyagi, "Estimation of toxic effects of chemically and biologically synthesized silver nanoparticles on human gut microflora containing Bacillus subtilis," Journal of Toxicology and Environmental Health Sciences, vol. 5, no. 9, pp. 172-177, 2013.

[37] B. Srinithya, V. V. Kumar, V. Vadivel, B. Pemaiah, S. P. Anthony, and M. S. Muthuraman, "Synthesis of biofunctionalized AgNPs using medicinally important Sida cordifolia leaf extract for enhanced antioxidant and anticancer activities," Materials Letters, vol. 170, pp. 101-104, 2016.

[38] J. Coates, "Interpretation of infrared spectra, a practical approach," in Encyclopedia of Analytical Chemistry, John Wiley \& Sons, Ltd, Chichester, UK, 2006.

[39] B. Ajitha, "Green synthesis and characterization of silver nanoparticles using Lantana camara leaf extract," Materials Science and Engineering: C, vol. 49, pp. 373-381, 2015.

[40] J. Baharara, F. Namvar, T. Ramezani, M. Mousavi, and R. Mohamad, "Silver nanoparticles biosynthesized using Achillea biebersteinii flower extract: apoptosis induction in MCF-7 cells via caspase activation and regulation of bax and 
bcl-2 gene expression," Molecules, vol. 20, no. 2, pp. 26932706, 2015.

[41] V. Kumar, D. K. Singh, S. Mohan, and S. H. Hasan, "Photoinduced biosynthesis of silver nanoparticles using aqueous extract of Erigeron bonariensis and its catalytic activity against acridine orange," Journal of Photochemistry and Photobiology B: Biology, vol. 155, pp. 39-50, 2016.

[42] P. K. Tyagi, R. Mishra, F. Khan, D. Gupta, and D. Gola, “Antifungal effects of silver nanoparticles against various plant pathogenic fungi and its safety evaluation on Drosophila melanogaster," Biointerface Research in Applied Chemistry, vol. 10, no. 6, pp. 6587-6596, 2020.

[43] F. Ö. Küp, S. Çoşkunçay, and F. Duman, "Biosynthesis of silver nanoparticles using leaf extract of Aesculus hippocastanum (horse chestnut): evaluation of their antibacterial, antioxidant and drug release system activities," Materials Science and Engineering: C, vol. 107, p. 110207, 2020.

[44] D. Sharma, L. Ledwani, T. Mehrotra, N. Kumar, N. Pervaiz, and R. Kumar, "Biosynthesis of hematite nanoparticles using Rheum emodi and their antimicrobial and anticancerous effects in vitro," Journal of Photochemistry and Photobiology B: Biology, vol. 206, p. 111841, 2020.

[45] D. Philip, "Honey mediated green synthesis of silver nanoparticles," Spectrochimica Acta Part A: Molecular and Biomolecular Spectroscopy, vol. 75, no. 3, pp. 1078-1081, 2010.

[46] P. K. Tyagi and S. Tyagi, "Evaluation of ascorbic acid contents in Hibiscus rosa-sinensis flowers and Citrus sinensis fruits," Research Journal of Pharmaceutical Biological and Chemical Sciences, vol. 9, no. 1, pp. 67-70, 2018.

[47] M. A. Khalilzadeh and M. Borzoo, "Green synthesis of silver nanoparticles using onion extract and their application for the preparation of a modified electrode for determination of ascorbic acid," Journal of Food and Drug Analysis, vol. 24, no. 4, pp. 796-803, 2016.

[48] N. T. T. Le, B. T. D. Trinh, D. H. Nguyen, L. D. Tran, C. H. Luu, and T. T. Hoang Thi, "The physicochemical and antifungal properties of eco-friendly silver nanoparticles synthesized by Psidium guajava leaf extract in the comparison with Tamarindus indica," Journal of Cluster Science, vol. 32, pp. 601-611, 2021.

[49] S. Raj, H. Singh, R. Trivedi, and V. Soni, "Biogenic synthesis of AgNPs employing Terminalia arjuna leaf extract and its efficacy towards catalytic degradation of organic dyes," Scientific Reports, vol. 10, no. 1, article 9616, 2020.

[50] L. Castillo-Henríquez, K. Alfaro-Aguilar, J. Ugalde-álvarez, L. Vega-Fernández, G. M. de Oca-Vásquez, and J. R. VegaBaudrit, "Green synthesis of gold and silver nanoparticles from plant extracts and their possible applications as antimicrobial agents in the agricultural area," Nanomaterials, vol. 10, no. 9, article 1763, 2020.

[51] A. Tripathi and R. Sirohi, "Antimicrobial activities of silver nanoparticles synthesized from peel of fruits and vegetables," Biological Insights, vol. 1, pp. 29-34, 2016.

[52] E. Burlacu, C. Tanase, N. A. Coman, and L. Berta, “A review of bark-extract-mediated green synthesis of metallic nanoparticles and their applications," Molecules, vol. 24, no. 23, p. $4354,2019$.

[53] B. Venkatadri, E. Shanparvish, M. R. Rameshkumar et al., "Green synthesis of silver nanoparticles using aqueous rhizome extract of Zingiber officinale and Curcuma longa: Invitro anti-cancer potential on human colon carcinoma HT-
29 cells," Saudi Journal of Biological Sciences, vol. 27, no. 11, pp. 2980-2986, 2020.

[54] A. K. Mittal, J. Bhaumik, S. Kumar, and U. C. Banerjee, "Biosynthesis of silver nanoparticles: elucidation of prospective mechanism and therapeutic potential," Journal of Colloid and Interface Science, vol. 415, pp. 39-47, 2014.

[55] T. Fafal, P. Taştan, B. S. Tüzün, M. Ozyazici, and B. Kivcak, "Synthesis, characterization and studies on antioxidant activity of silver nanoparticles using Asphodelus aestivus Brot. aerial part extract," South African Journal of Botany, vol. 112, pp. 346-353, 2017.

[56] R. Upadhyay, J. K. Chaurasia, K. N. Tiwari, and K. Singh, "Antioxidant property of aerial parts and root of Phyllanthus fraternus Webster, an important medicinal plant," Scientific World Journal, vol. 2014, article 692392, 7 pages, 2014.

[57] A. Watanabe, M. Kajita, J. Kim et al., "In vitro free radical scavenging activity of platinum nanoparticles," Nanotechnology, vol. 20, no. 45, article 455105, 2009.

[58] K. H. Oh, V. Soshnikova, J. Markus et al., "Biosynthesized gold and silver nanoparticles by aqueous fruit extract of Chaenomeles sinensisand screening of their biomedical activities," Artificial Cells, Nanomedicine, and Biotechnology, vol. 46, no. 3, pp. 599-606, 2018. 